\title{
Sob os ventos da mudança climática: desafios, oportunidades e o papel da função produção no contexto do aquecimento global
}

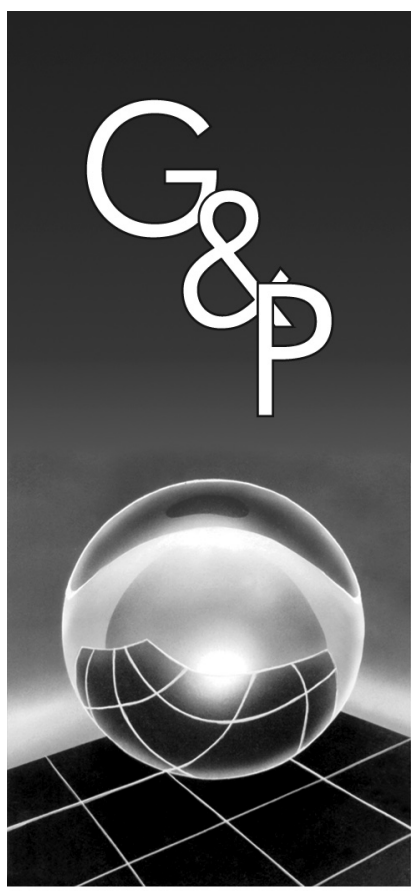

\author{
Charbel José Chiappetta Jabbour \\ Fernando César Almada Santos
}

\begin{abstract}
Resumo
O objetivo deste artigo é lançar luzes sobre as implicações da mudança climática para as organizações. Para fazer frente a esse debate, são explorados: o conceito de "inteligência ambiental" (IA); as estratégias por meio das quais as organizações fazem frente ao desafio da mudança climática; as oportunidades que explicam a adoção dessas estratégias; e o papel fornecido pela função produção para que tais estratégias possuam o efeito desejado. Por fim, tais conceitos são sistematizados, buscando-se uma integração dos modelos teóricos existentes, até então considerados de maneira estanque.
\end{abstract}

Palavras-chave: Mudança climática. Função produção. Inteligência ambiental. Aquecimento global.

\section{Introdução}

A temática da mudança climática alterou radicalmente a pauta de discussão sobre os grandes temas e dilemas da atualidade. Inúmeros são os alertas sobre os problemas ambientais decorrentes do aquecimento global e, principalmente, acerca de seus efeitos para o futuro da espécie humana, suas condições de vida e seu sistema de produção. Se antes, os diagnósticos de problemas ambientais eram tidos como preciosismos científicos de uma elite encastelada em suas torres de marfim ambientalmente radicalizadas, hoje, informações sobre aquecimento global, Protocolo de Kyoto, mudanças climáticas e tecnologias ambientais vêm se tornando rotineiramente conhecidas, difundindo-se pela sociedade. São os ventos da mudança.

$\mathrm{Na}$ esteira da mudança climática, muitos dirigentes organizacionais verificam, com temor, a ascensão de novos desafios, oportunidades e posicionamentos para suas organizações. Até meados da década de 1990, a maior parte das empresas possuía uma postura reativa frente à temática da mudança climática. Mas a formalização e a ratificação do Protocolo de Kyoto por importantes países, bem como as preocupantes divulgações sobre o aquecimento global sistematizadas pelo painel intergovernamental sobre mudança climática (IPCC, na sigla em inglês), tornaram-se um pano de fundo em que se revelam múltiplas posturas organizacionais (SCHULTZ; WILLIAMSON, 2005).

Seguindo tal linha argumentativa, Kolk e Pinkse (2004) afirmam que o efeito da mudança climática sobre as firmas dependerá, principalmente, do nicho de mercado por elas explorado. Como corolário dessa assertiva, os autores indicam que as empresas enfrentam um crescimento gradual de desafios, atrelado, necessariamente, ao grau de adoção de combustíveis fósseis em seus produtos e processos produtivos. Por exemplo, no extremo mais crítico dos desafios impostos pelo panorama de mudanças climáticas, encontram-se as empresas da indústria petrolífera, como as grandes Shell, ExxonMobile, BP, Petrobrás, entre outras, as quais vêm investindo na prospecção e desenvolvimento de tecnologias alternativas e limpas. Entretanto, alterações tendem a ocorrer em uma ampla gama de indústrias e quiçá na totalidade delas. Como afirma Boiral (2006), citando uma pesquisa conduzida pelo Financial Times com as 500 maiores empresas do mundo, $80 \%$ dos entrevistados acreditam que a mudança climática afetará os rumos de seus negócios. Acredita-se que as maiores transformações serão realizadas no contexto da função produção, em termos de desenvolvi- 
mento de produto e processos, de logística e de gestão da qualidade (GAUGHRAN; BURKE; PHELAN, 2007; ANGELL; KLASSEN, 1999).

Consequentemente, os argumentos aqui expostos gravitam ao redor dos seguintes problemas de pesquisa: Quais são os mecanismos de gestão, estratégias empresariais e fatores que motivam as organizações a lidarem com os efeitos da mudança climática em seus negócios? Qual o papel da função produção e de suas atividades no processo de mitigação do aquecimento global pelas empresas? Para fazer frente a tais indagações, este artigo possui o objetivo de:

a) Explorar os efeitos gerados pelas mudanças climáticas no contexto organizacional, destacando os acordos voluntários estabelecidos para a redução de emissões de gases do efeito estufa (GEE) e a necessidade de estabelecimento de uma inteligência ambiental (IA) nas organizações (Seção 2);

b) Identificar as estratégias individuais, industriais e intersetoriais que as empresas podem explorar para fazer frente aos imperativos da mudança climática (Seção 3);

c) Sintetizar as principais motivações para as alterações empreendidas pelas empresas, para um melhor entendimento das causas e consequências dos acordos voluntários de redução das emissões de GEE (Seção 4);

d) Tratar tais temáticas de forma integrada, por meio da proposição de uma sistematização na qual se aliam IA, estratégias de mitigação das emissões de GEE e suas motivações, explicitando as potencialidades e desafios para a função produção no contexto do aquecimento global (Seção 5); e

e) Identificar hipóteses para serem exploradas em pesquisas vindouras (Seção 6).

\section{Mudança climática, desafios e oportunidades: uma questão de inteligência ambiental}

Uma rápida visita ao website das empresas que recorrentemente frequentam os mais prestigiosos rankings empresariais do mundo fornece uma boa visão das transformações que vêm ocorrendo nessas organizações, por conta da mudança climática. No site da petrolífera BP, há uma campanha de conscientização, para que seus consumidores reduzam as taxas de emissão de GEE (BP, 2006). Em outras iniciativas, como o Carbon Disclosure Project, mais de 1.000 empresas prestam contas sobre seu padrão de emissões de GEE e participam de pesquisas sobre os efeitos das mudanças climáticas no contexto dos negócios (CD PROJECT, 2007).

Para Boiral (2006), a ST Microelectronics constitui um caso emblemático dessas transformações. Tal empresa anunciou, em meados de 2006, seu comprometimento com a redução de $50 \%$ no volume de emissões de GEE até 2010. Na década passada, tal empresa foi agraciada com diversos prêmios por seus esforços para reduzir as emissões de GEE. Tais reduções foram obtidas pela condução de inúmeros projetos, como a inserção da dimensão ambiental no sistema de avaliação do desempenho dos diretores de suas fábricas, incentivos para que seus funcionários passem a utilizar mais o transporte coletivo a outras formas de transporte e financiamento de projetos de reflorestamento em diversos países.

Controlar as emissões de GEE não é questão, apenas, de monitorar o volume lançado e estabelecer metas conducentes à sua redução. Um número considerável de empresas pretende utilizar as perspectivas da mudança climática para fins de controle interno: empresas manufatureiras vêm inserindo aspectos ambientais em seu processo de inovação (KUEHR, 2007); instituições bancárias vêm incluindo indicadores de emissão de GEE em seus processos de tomada de decisão sobre investimentos (DLUGOLECKI; LAFELD, 2005); um grande número de empresas vem surgindo para explorar, exclusivamente, o mercado de tecnologias limpas, com ênfase na mitigação das emissões de GEE (SMITH, 2001).

Apesar de diferenças e nuanças, posturas empresariais pró-ativas exigem o estabelecimento do que Boiral (2006) conceitua como Inteligência Ambiental (IA), cuja necessidade tende a se tornar mais crítica com as divulgações realizadas pelo IPCC (TONN, 2007). A IA é considerada um construto que envolve quatro variáveis, as quais se inter-relacionam, em um mecanismo de influência mútua. De forma geral, apregoa-se que as empresas, para enfrentar os desafios e explorar as oportunidades fomentadas pela mudança climática, devem constantemente diagnosticar: questões econômicas; políticas e de legislação; sociais; e científicas e técnicas, a fim de consolidar uma estratégia pró-ativa (Figura 1).

As questões econômicas monitoram oportunidades de mercado e os riscos vinculados às estratégias de redução das emissões de GEE, com foco na exploração de vantagens competitivas. A análise econômica deve ser acompanhada de uma análise sobre tendências da legislação ambiental nos países e nas indústrias em que a empresa opera, com ênfase nos subsídios fornecidos para iniciativas de redução de emissões de GEE. As questões de cunho social, como pressões exercidas por grupos da sociedade civil organizada, podem influenciar diretamente a imagem e atestar ou colocar em dúvida a legitimidade das empresas em suas ações de redução de emissões dos GEE, bem como influenciar, positiva ou negativamente, a motivação dos funcionários em permanecer e planejar suas carreiras nessas empresas. Por fim, para materializar seus almejos e expectativas quanto às oportunidades geradas, as firmas devem materializar suas ações, amparando atividades de pesquisa 


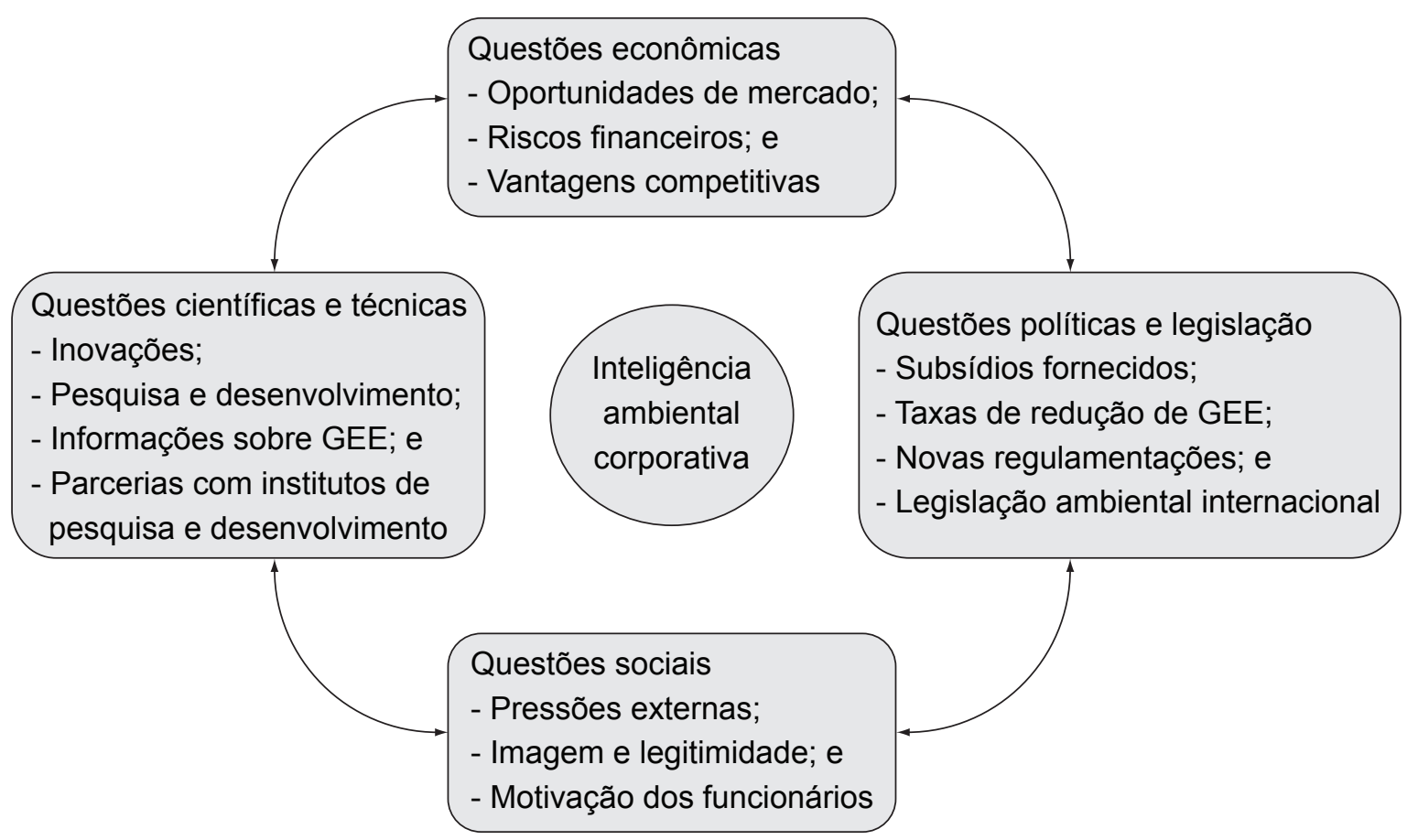

Figura 1. A inteligência ambiental empresarial: prospecções sobre a mudança climática, adaptado (BOIRAL, 2006).

e desenvolvimento, pautadas em banco de dados e informações sobre emissões de GEE. Por sua complexidade, o processo de inovação que considera questões de mitigação das emissões de GEE tende a envolver parcerias com institutos de pesquisa e universidades (BOIRAL, 2006).

$\mathrm{O}$ esforço em busca de uma IA dinâmica e pró-ativa pode ser realizado individualmente ou de forma setorial. Um prestigioso caso de IA setorial é o consórcio EIATRACK (2007). O EIATRACK é uma organização sem fins lucrativos, fomentada pelas empresas líderes mundiais no setor de produtos eletrônicos e que operam no mercado global, visando atualização diária, com informações ambientais provenientes dos diversos países. O objetivo é que o portal forneça às empresas associadas informações ambientais que são úteis no processo de inovação tecnológica e que atenda aos padrões mundiais de adequação ambiental de produtos eletrônicos, explorando as questões apresentadas na Figura 1. As diversas combinações, ênfases e decisões que delineiam as chamadas estratégias empresariais frente à mudança climática são apresentadas a seguir.

\section{Posicionamentos estratégicos ante a mudança climática}

A consolidação das temáticas ambientais no seio empresarial é marcada, fundamentalmente, pela análise evolutiva de práticas de gestão ambiental. De fato, inúmeras são as contribuições para se avaliar a estratégia de gestão ambiental das empresas. Nesses casos, são propostas tipologias de gestão ambiental, que tendem a explorar três, quatro ou cinco níveis de maturidade da gestão ambiental empresarial. Apesar da utilidade desses modelos mais genéricos para a análise da gestão ambiental empresarial, não foram identificadas pesquisas brasileiras que enfoquem a discussão sobre as diferentes estratégias com que as empresas podem tratar os desafios da mudança climática.

Dessa forma, as pesquisas conduzidas por Kolk e Pinkse (2004; 2005) adquirem valor especial e merecem ser discutidas com maior atenção, uma vez que constituem os principais estudos e propostas acerca das estratégias organizacionais frente ao aquecimento global. Em sua primeira pesquisa (KOLK; PINKSE, 2004), os autores classificaram seu modelo como "estratégias mercadológicas para a mudança climática" e, posteriormente (KOLK; PINKSE, 2005), atribuíram-lhe o nome de "estratégias emergentes das empresas para a mudança climática".

De forma geral, Kolk e Pinkse $(2004$; 2005) postulam que as empresas possuem seis respostas ante o desafio da mudança climática (Quadro 1). Essa escala de comportamentos emerge das múltiplas combinações de dois fatores:

a) Intenção estratégica, isto é, discute-se qual o principal objetivo a ser alcançado pelas ações de mitigação de aquecimento global conduzidas pelas empresas. A intenção estratégica objetiva um posicionamento sobre duas ações: (a) inovar, tornando-se diretamente criadora de novas perspectivas em mudança climática; ou (b) explorar os mecanismos de compensação existentes, principalmente os gerados pelo protocolo de Kyoto, podendo a 
Quadro 1. Opções estratégicas para as organizações enfrentarem a mudança climática (KOLK; PINKSE, 2005).

\begin{tabular}{|c|c|c|c|}
\hline & \multicolumn{2}{|c|}{ Principal Objetivo } \\
\hline & & Inovação & Compensação \\
\hline ని & Interno (organização) & Melhorias em processos (1) & Transferências internas (2) \\
\hline$\stackrel{\widetilde{\pi}}{=}$ & Vertical (cadeia de fornecedores) & Desenvolvimento de produtos (3) & Mensuração da cadeia de suprimentos (4) \\
\hline 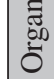 & $\begin{array}{l}\text { Horizontal (para além da cadeia de } \\
\text { fornecedores) }\end{array}$ & Novos produtos/novos mercados (5) & Aquisição de créditos de emissões de GEE (6) \\
\hline
\end{tabular}

empresa decidir por uma estratégia de "comprar" ou "vender" no mercado mundial de GEE. A principal diferença entre essas dimensões é que a primeira requer que a empresa utilize diretamente sua capacidade de inovação e competências, e a segunda, que ela realize aquisições que se originam no potencial de inovação e competências de outras empresas; e

b) Arquitetura da organização, que indica o grau de cooperação e mobilização de agentes dentro das organizações, na cadeia em que a empresa opera e para além dessa cadeia. Assim, a empresa pode: (a) agir de forma individual; (b) explorar uma estratégia para o seu segmento industrial e cadeia em que atua; ou (c) estabelecer parcerias para além de sua cadeia ou indústria, como, por exemplo, envolvendo organizações públicas não-estatais.

Cada uma dessas duas dimensões possui diversas combinações, no entanto, podem ser identificadas seis posturas estratégicas das organizações ante o desafio da mudança climática. Cada um desses posicionamentos tende a ser predominante em um dado setor industrial, dependendo da forma por meio da qual os dirigentes empresariais percebem, em termos de riscos e oportunidades, cada uma dessas estratégias (KOLK; PINKSE, 2005).

Quando o objetivo da estratégia de mitigação da mudança climática é a inovação, cabe destaque às estratégias 1,3 e 5 . Na estratégia 1, a organização assume o dever de monitorar e reduzir a emissão de GEE resultante de seu processo produtivo. Adota-se, com tal estratégia, a postura de autodesenvolvimento de tecnologias ambientais focadas na redução de emissões, eficiência energética e busca por fontes alternativas de energia. Na estratégia 3, a empresa foca o desenvolvimento de produto que atende aos novos padrões de emissão de GEE. Geralmente, busca-se adequação aos padrões setoriais e o envolvimento da cadeia de fornecedores, para que o esforço da firma em mitigar a mudança climática seja acompanhado de contribuições de fornecedores, com foco no padrão exigido pelos consumidores de um dado setor. $\mathrm{O}$ posicionamento 5 implica a constituição de redes organizacionais entre setores, para além de uma dada cadeia. Um exemplo desse tipo de estratégia é parceria estabelecida entre algumas empresas das indústrias de petróleo, automobilística e centros de pesquisa e desenvolvimento, a fim de desenvolverem tecnologias pautadas em células de combustível (KOLK; PINKSE, 2005).

As estratégias 2, 3 e 6 podem ser melhor compreendidas no contexto de organizações que não possuem como objetivo reduzir, diretamente, suas emissões de GEE. Valem-se da estratégia 2, geralmente, grandes corporações, que transferem suas unidades produtivas, localizadas em países em que a regulamentação sobre emissões de GEE torna-se crescentemente rigorosa, para países em que a legislação é mais branda. O posicionamento 4 envolve o grupo de organizações que prefere mesurar a eficiência de emissões de GEE dos inputs disponíveis no mercado e alterar os utilizados atualmente. Ao invés de conduzirem processos de inovação, substituem componentes, a fim de adotar aqueles que menos emitem GEE. Empresas que adotam o posicionamento 6 preferem explorar o comércio internacional de GEE, por meio dos mecanismos estabelecidos pelo Protocolo de Kyoto. Tais organizações podem comprar certificados de redução de emissões (KOLK; PINKSE, 2005).

As organizações podem adotar uma única estratégia, combinar várias ou não se posicionar. Segundo Boiral (2006), essas posturas dependem de como os dirigentes empresariais compreendem a mudança climática, como entendem as oportunidades e desafios gerados por esses novos ventos. Quanto maior for o número de dirigentes que perceberem na mitigação da mudança climática uma oportunidade para a organização, mais as empresas se concentrarão em objetivos de inovação. A próxima seção lança luzes sobre as categorias de oportunidades geradas pela mudança climática.

\section{Explorando oportunidades}

Sistematizar as oportunidades organizacionais que emergem da exploração de estratégias para a mitigação da mudança climática conduz, necessariamente, à pesquisa de Hoffman (2005). Esse autor sistematizou sete categorias (Quadro 2) que podem gerar vantagens competitivas para as empresas que formulam tais estratégias, e que podem explicar acordos voluntários, individuais ou setoriais, para a redução de emissões de GEE.

Muitas dessas motivações já haviam sido sistematizadas em pesquisas sobre gestão ambiental empresarial. Entretanto, a abordagem de Hoffman (2005) permite uma evidência do que o autor considera ser a lógica empre- 
Quadro 2. Oportunidades organizacionais frente à mudança climática. (HOFFMAN, 2005).

\begin{tabular}{|c|c|}
\hline Oportunidades & Importância Estratégica \\
\hline Melhoria operacional & $\begin{array}{l}\text { A prevenção da poluição e das emissões de GEE pode gerar uma grande oportunidade para a em- } \\
\text { presa melhorar suas operações. Seja por meio do reuso, reciclagem ou reutilização, seja por meio da } \\
\text { melhoria da ecoeficiência de processos e produtos. Essas melhorias tendem a gerar redução nos cus- } \\
\text { tos de energia, pela substituição das fontes até então adotadas por fontes mais limpas e renováveis. } \\
\text { Por exemplo, a busca por novas formas de transporte para distribuição de produtos pode gerar, além } \\
\text { de redução das emissões de GEE, oportunidades para reduzir custos de transporte. }\end{array}$ \\
\hline $\begin{array}{l}\text { Antecipação e influência sobre } \\
\text { as regulamentações de mudança } \\
\text { climática }\end{array}$ & $\begin{array}{l}\text { Implica o entendimento da atual legislação, acordos e exigências quanto às taxas de emissão de GEE } \\
\text { pelas organizações. A adequação aos padrões globais de emissão de GEE permite que a empresa } \\
\text { opere e disponibilize seus produtos de forma global, sem restrições desconhecidas. Além disso, a } \\
\text { organização pode assumir um papel de liderança, a fim de influenciar um recrudescimento na regu- } \\
\text { lamentação sobre emissões de GEE, engendrando cenários competitivos que explorem e favoreçam } \\
\text { a postura pró-ativa, ainda não adotada pelos concorrentes. }\end{array}$ \\
\hline Acesso a novas fontes de capital & $\begin{array}{l}\text { Empresas dispostas a reduzir suas taxas de emissões de GEE possuem acesso a novas fontes de } \\
\text { crédito, que visam fomentar a adoção de tecnologias de processo mais limpas. Dessa forma, conco- } \\
\text { mitantemente à renovação tecnológica, melhoria operacional e outros benefícios, a organização tem } \\
\text { acesso a fontes de financiamento até então indisponíveis. }\end{array}$ \\
\hline Reduzir o risco de gestão & $\begin{array}{l}\text { Um posicionamento pró-ativo quanto à mudança climática permite às organizações reduzir os riscos } \\
\text { inerentes à gestão empresarial no contexto do aquecimento global. Tais empresas tendem a possuir } \\
\text { um sistema de emergência para lidar com catástrofes ambientais geradas pelo aquecimento global. } \\
\text { Não obstante, estarão preparadas para lidar com taxas, multas e outras cobranças vinculadas ao } \\
\text { desempenho das emissões de GEE. }\end{array}$ \\
\hline Elevar a reputação corporativa & $\begin{array}{l}\text { Assumir publicamente a adoção de uma estratégia para fazer frente à mudança climática e colocá-la } \\
\text { em prática tende a elevar a reputação, respeito, conhecimento e difusão das atividades e marcas de } \\
\text { uma dada organização para a sociedade. }\end{array}$ \\
\hline $\begin{array}{l}\text { Identificar novas oportunidades } \\
\text { mercadológicas }\end{array}$ & $\begin{array}{l}\text { O debate sobre emissões de GEE pode evidenciar para a organização diversas fontes de dados, } \\
\text { informantes, tendências e normas que até então não recebiam a devida atenção, o que tende à explo- } \\
\text { ração de novas oportunidades mercadológicas, cujo sucesso encontra-se vinculado ao pioneirismo } \\
\text { da estratégia de marketing e sua relação com a temática das mudanças climáticas. }\end{array}$ \\
\hline $\begin{array}{l}\text { Melhorar a gestão de recursos } \\
\text { humanos }\end{array}$ & $\begin{array}{l}\text { A exploração de uma estratégia ante a mudança climática tende a oferecer diversos benefícios para } \\
\text { as organizações. Tais benefícios podem levar a empresa a liderar processos de inovação, criar novas } \\
\text { oportunidades de negócio, fomentando planos de carreira, salários, benefícios, confiança e desem- } \\
\text { penho superior de seus funcionários. }\end{array}$ \\
\hline
\end{tabular}

sarial por trás dos acordos voluntários para redução de emissões de GEE. A exploração dessas oportunidades demanda diferentes contribuições da função produção, o que é tratado a seguir.

\section{0 papel da função produção no contexto do aquecimento global}

A função produção aqui é definida como o conjunto “de recursos manejados na tarefa manufatureira propriamente dita, podendo referir-se tanto aos equipamentos e instalações como aos métodos de organização da produção e de controle da qualidade" (CORAZZA, 2003).

Por sua orientação essencialmente transformadora, a função produção é aquela que apresenta maior potencial de geração ou mitigação dos impactos ambientais de uma firma (CORAZZA, 2003). Donaire (1999) afirma que os inputs do sistema produtivo estão diretamente relacionados, na maior parte dos casos, a um conjunto de recursos naturais explorados e os outputs relacionados à geração de impactos ambientais, que afetam a capacidade de suporte do planeta.

Dessa forma, segundo Rothenberg, Pill e Maxwell (2001), as decisões concernentes à gerência de sistemas produtivos possuem implicações sobre a relação entre empresa e meio ambiente natural, uma vez que é plausível assumir que as eventuais ineficiências de um dado sistema produtivo tendem a coincidir com os altos níveis de poluição registrados pela empresa. No estágio ótimo de introdução da dimensão ambiental nas atividades de produção (FLORIDA, 1996), as questões ambientais passam a permear e determinar diversas decisões da manufatura. É válido, para tal entendimento, o modelo clássico (Figura 2) proposto por Angell e Klassen (1999), no qual as questões ambientais afetam as decisões da função produção, em suas várias facetas.

A importância crescente da dimensão ambiental para a empresa e o reconhecimento da imprescindibilidade da função produção para esse tema possuem como 


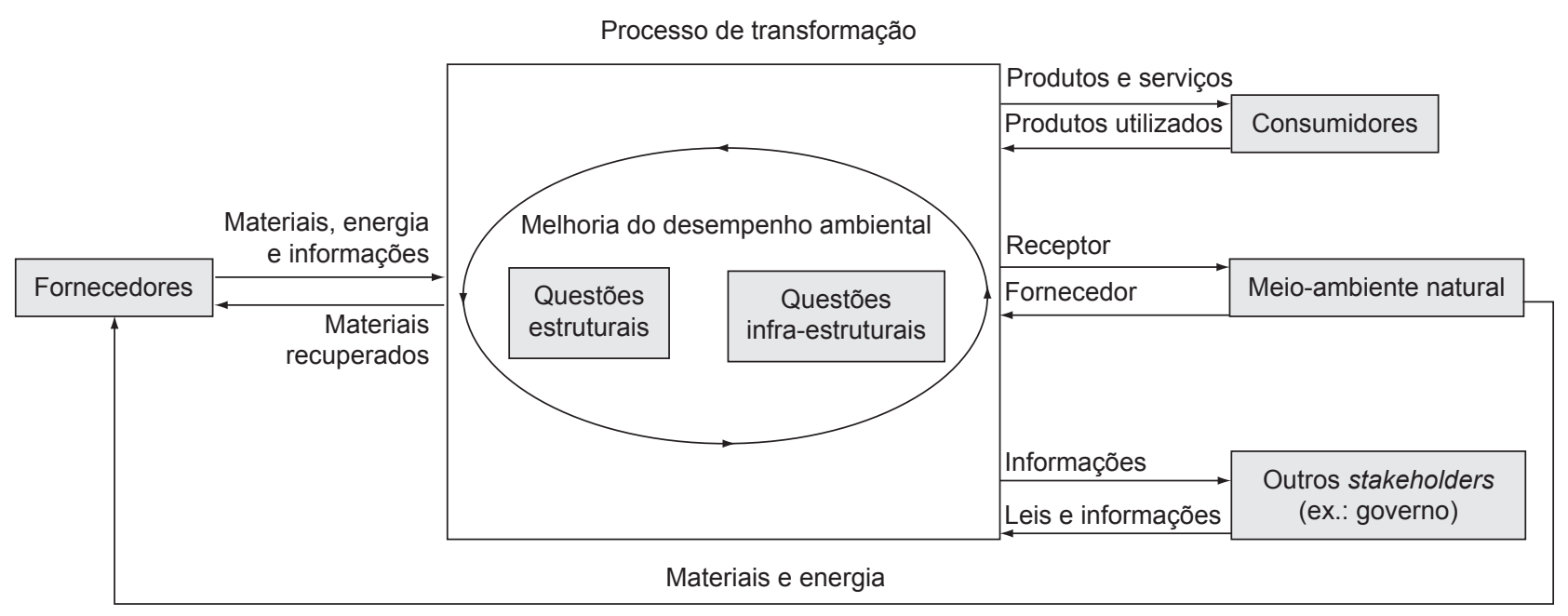

Figura 2. Integrando a questão ambiental nas decisões e relações da função produção (ANGELL; KLASSEN 1999).

corolário a aceitação, por alguns estudiosos (JIMÉNEZ; LORENTE, 2001; ANGELL; KLASSEN, 1999; SARKIS; RASHEED, 1995), da questão ambiental como um novo objetivo de desempenho da manufatura, ao lado das prioridades clássicas de custo, flexibilidade, qualidade e velocidade das entregas. Assim sendo, a dimensão ambiental, enquanto novo objetivo de desempenho da produção fomenta suas congêneres competitivas:

a) O objetivo de desempenho de custo é potencializado pelas ações de gestão ambiental, que tendem a diminuir os desperdícios, estimular a descoberta de novas matérias-primas, induzindo a reutilização e reciclagem de materiais. Essas medidas ambientais tendem a reduzir o custo por unidade produzida em uma dada empresa;

b) A gestão ambiental pró-ativa possui como consequência a mitigação dos impactos ambientais e da eclosão de acidentes ambientais, contribuindo para que os prazos agendados para as entregas de produtos aos consumidores sejam cumpridos;

c) A consideração da dimensão ambiental no desenvolvimento de produtos leva a empresa à prospecção de inovações ambientalmente adequadas, o que potencializa a flexibilidade da produção de uma dada empresa; e

d) A gestão ambiental pró-ativa incrementa os objetivos da gestão da qualidade, que deve atender aos almejos dos consumidores ambientalmente responsáveis.

Geralmente, a adoção de uma estratégia de redução de missões de GEE exige diversas contribuições da função produção, as quais se materializam por meio de transformações em quatro atividades, da seguinte forma:

a) Desenvolvimento de processos: à luz de uma estratégia de mitigação da mudança climática, busca-se o desenvolvimento de processos produtivos pautados na constante redução de emissões de GEE. O foco é no desenvolvimento ou aquisição de tecnologias mais limpas ou totalmente limpas, conforme proposto por Kuehr (2007);

b) Desenvolvimento de produto: novos produtos ou produtos já existentes passam a incorporar, em todas as etapas de seu processo de desenvolvimento, a redução constante de emissões de GEE. A seleção de idéias privilegia propostas adequadas às normas internacionais de emissões de GEE, influenciando as demais fases do desenvolvimento, até a pós-venda do produto, para se evitar que o descarte de um dado produto ocorra de forma inadequada, implicando geração de GEE, na mesma linha de raciocínio desenvolvida por Tingström e Karlsson (2006);

c) A gestão da qualidade adquire um escopo mais amplo. A qualidade torna-se um construto mais amplo e sua gestão requer atenção para as taxas de emissões de GEE do produto final e de seu processo de fabricação. As metodologias, métodos e técnicas da gestão da qualidade incorporam componentes da estratégia de mudança climática adotada pela empresa, conforme tratado de forma mais ampla por Aboulnaga (1998); e

d) As atividades logísticas tendem a privilegiar a aquisição de componentes com reduzida taxa de emissões de GEE. A armazenagem de tais componentes deve evitar que acidentes geradores de GEE ocorram. As atividades de transporte, dos inputs ou dos outputs, são repensadas à luz da busca por fontes alternativas de energia e combustíveis não-fósseis, optando-se por aquelas com reduzidos padrões de emissões de GEE, conforme proposição de Wu e Dunn (1995).

A despeito das contribuições efetuadas por Boiral (2006), Kolk e Pinkse (2005) e por Hoffman (2005), tais pesquisas mostram-se aos pesquisadores em gestão e 
dirigentes organizacionais como estanques. Além disso, tais pesquisadores não lançam luzes sobre as implicações de seus trabalhos para a função produção organizacional, considerada fundamental na melhoria do desempenho ambiental da firma, e, consequentemente, imprescindível para as estratégias de mitigação do aquecimento global que uma organização venha a adotar.

Assim, a presente contribuição reside na proposição de uma sistematização que correlaciona os tipos de estratégias de mitigação da mudança climática que uma empresa pode adotar (KOLK; PINKSE, 2005), as diversas contribuições que a IA organizacional pode fornecer para o posicionamento mais adequado (BOIRAL, 2006), tendo em vista as motivações discutidas por Hoffman (2005), bem como as principais contribuições da função produção em cada uma das estratégias possíveis. O Quadro 3 fornece um entendimento matricial que tais variáveis tendem a apresentar.

Quando a organização posiciona-se com uma estratégia de mitigação de mudança climática pautada em melhorias em processo (estratégia 1) (KOLK; PINKSE, 2005), as contribuições da IA tendem a se manifestar analisando processos que reduzam custos de transformação ao mesmo tempo que reduzem as emissões de GEE, segundo os padrões legais identificados, por meio da adoção de tecnologias de processamento identificadas junto a institutos de pesquisa e desenvolvimento. A principal motivação é a melhoria operacional que o processo pode adquirir. O papel da função produção concentra-se em participar do processo de tomada de decisão explorando suas competências em desenvolvimento de processos.

Ao buscar uma estratégia de transferência interna (estratégia 2) (KOLK; PINKSE, 2005) os dirigentes organizacionais requerem uma IA que forneça informações válidas sobre, fundamentalmente, aspectos econômicos e de legislação. Assim, a empresa poderá migrar para países do globo em que há condições para redução dos custos operacionais e uma regulamentação mais branda em termos de emissões de GEE. As potencialidades de uma estratégia de mitigação da mudança climática em termos de gerações de oportunidades para a empresa tendem a ser ignoradas nesse estágio, o qual não requer o papel determinante da função produção. As competências desenvolvidas por tal função serão necessárias para a implantação e operação da unidade alhures, apenas.

A estratégia de desenvolvimento de produtos (estratégia 3) (KOLK; PINKSE, 2005) tende a envolver uma análise sobre questões econômicas, de legislação e científicas, a fim de se verificar a viabilidade

Quadro 3. O papel da função produção para o entendimento dos modelos de Boiral (2006), de Kolk e Pinkse (2005) e de Hoffman (2005).

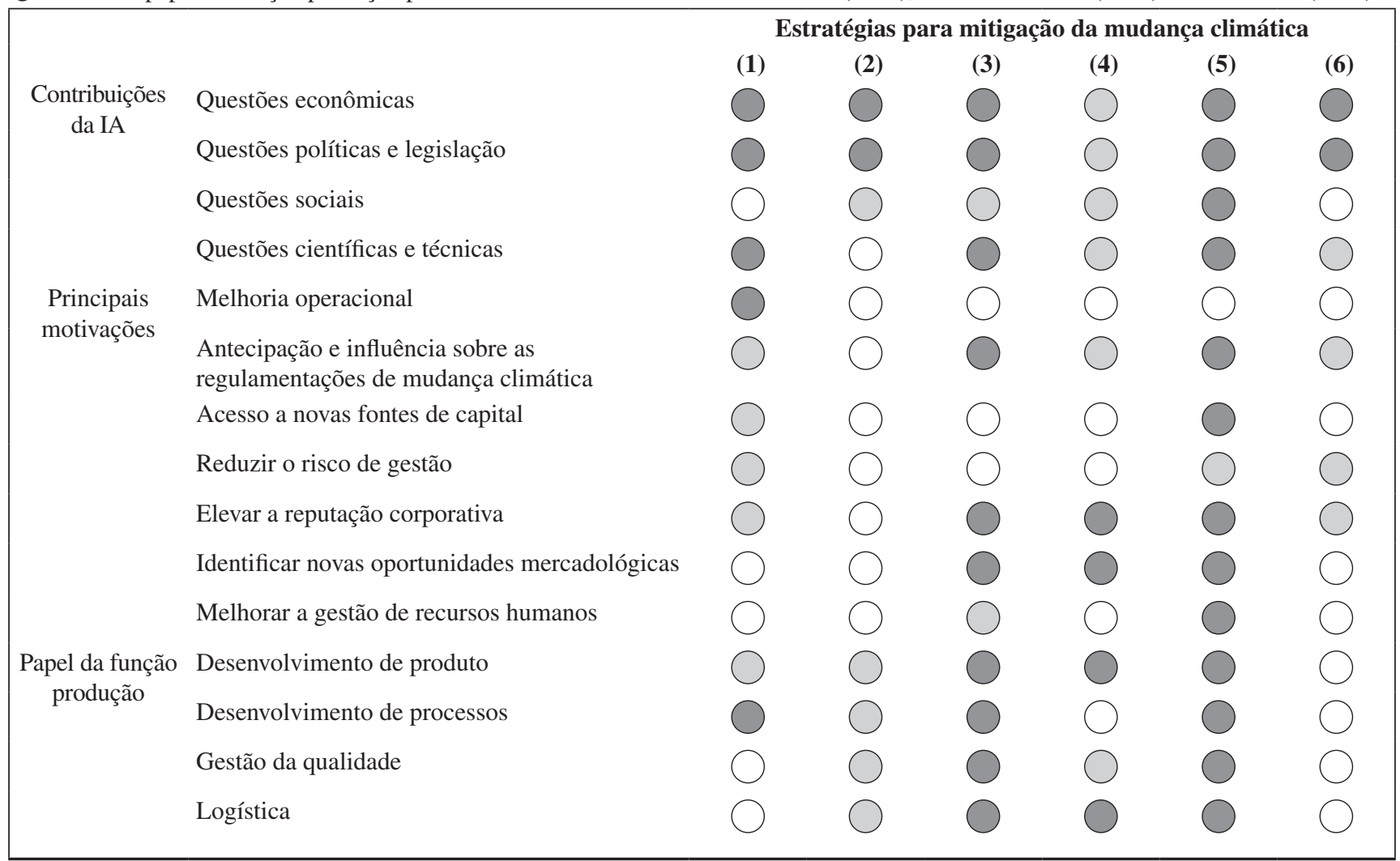

(1) Melhorias em processos; (2) transferências internas; (3) desenvolvimento de produtos; (4) mensuração da cadeia de suprimentos; (5) novos produtos/novos mercados; (6) aquisição de créditos de emissões de GEE; $\bigcirc$ : ausente; $\bigcirc$ : moderado; e $\bigcirc$ : presente. 
de transformações no desenvolvimento de produtos, com enfoque na redução de emissões de GEE. Ao adotar tal estratégia, a organização pode se antecipar a normas internacionais sobre o desempenho ambiental de produtos, destacando-se na indústria em que opera e auferindo oportunidades mercadológicas e melhor reputação junto ao mercado consumidor. Nesse tipo de estratégia, a função produção tende a desempenhar um papel crítico: deve desenvolver produtos com reduzido padrão de emissões de GEE, fabricados por processos que empreguem tecnologias limpas, cuja qualidade e atividades logísticas incorporem exigências relativas à redução de emissões de GEE.

A adoção da estratégia 4 (KOLK; PINKSE, 2005), de mensuração da cadeia de suprimentos, requer uma contribuição intermediária da IA, com informações básicas sobre quais os melhores inputs em termos de redução de emissões de GEE. A principal motivação para esse posicionamento é elevar a reputação da organização, explorando segmentos mercadológicos em que os inputs, antes utilizados, despertavam desconfiança nos consumidores. A função produção deve estar preparada para alterar os componentes dos produtos e identificar fornecedores que possuam tais matérias-primas alternativas.

A estratégia 5 (KOLK; PINKSE, 2005) - novos produtos e novos mercados - implica o estabelecimento de diversos relacionamentos e onde cada um deles possui um papel crítico. Cabe à IA identificar novos mercados e produtos e que sejam fomentados pelo recrudescimento da regulamentação em emissões de GEE e pela identificação de forças políticas que possam assumir o poder público defendendo novos posicionamentos das organizações ante a mudança climática. A IA deve identificar os stakeholders interessados nos novos produtos a serem gerados, de forma a verificar conflitos e buscar soluções para tecnologias cuja adoção seria polêmica.

Nesse contexto, surge a necessidade de se prospectar junto a institutos de pesquisa e desenvolvimentos as tendências tecnológicas no contexto do aquecimento global. Com isso, a organização poderá se antecipar às legislações futuras e liderar mercados ambientalmente adequados, elevando sua reputação, auferindo vantagens mercadológicas e proporcionando o desenvolvimento das competências dos funcionários para esse processo de inovação, que tende a garantir oportunidade de crescimento da organização, com aumento das oportunidades de carreira, treinamento e desenvolvimento aos seus funcionários. Cabe, pois, à função produção o papel de desenvolver novos produtos com reduzidas emissões de GEE, em parceria com fornecedores que possuam condições de atender a tais exigências, garantindo que os mesmos sejam manufaturáveis conforme os novos padrões de qualidade.
Por fim, ao se posicionar adotando a estratégia 6 (KOLK; PINKSE, 2005) - aquisição de créditos de emissões de GEE - os dirigentes organizacionais necessitam que a IA mapeie as oportunidades econômicas dessa transação, a fim de que ela seja juridicamente viável e atenda aos padrões legais de emissões de GEE. Tal estratégia não visa explorar as oportunidades identificadas por Hoffman (2005) e tende a não demandar apoio da função produção.

\section{Considerações finais}

O presente artigo lança luzes sobre as implicações da mudança climática para as organizações, explorando as oportunidades e desafios que esses novos ventos trazem aos dirigentes organizacionais. A adoção de uma estratégia para fazer frente à mudança climática exige que as organizações capacitem-se em inteligência ambiental, de maneira individual, setorial ou intersetorial. A percepção de oportunidades e desafios delineia um grupo amplo de posicionamentos organizacionais.

Grande parte desses posicionamentos exige um papel intensivo da função produção, principalmente em organizações que focam a inovação, com implicações para o desenvolvimento de novos processos e produtos. Quanto mais inovadora a proposta para lidar com o aquecimento global, mais decisiva torna-se a função produção para o êxito dessas propostas.

As implicações dessa afirmação são diversas e devem possuir reflexos sobre duas principais esferas: organizacional e educacional. No contexto organizacional, deve-se considerar a importância da temática da mudança climática para a continuidade dos negócios da empresa, considerando-se a função produção como parceira na tomada de decisões estratégicas. Por outro lado, as implicações para a formação em engenharia de produção exigem a incorporação de questões interdisciplinares, pautadas na resolução de problemas ambientais da atualidade.

Para facilitar a condução de pesquisas futuras neste campo do conhecimento, recomenda-se a investigação das seguintes hipóteses:

a) Quanto mais estruturada for a "inteligência ambiental" da organização, mais facilmente ela poderá explorar as diversas oportunidades geradas pela mudança climática;

b) As diversas estratégias empresariais para a mitigação da mudança climática estão diretamente relacionadas aos diversos tipos de indústria em que uma firma pode atuar;

c) Estratégias de mitigação do aquecimento global que focam o envolvimento de diversos atores, a cadeia de suprimentos e para além dela requerem 
o desenvolvimento de uma "inteligência ambiental" compartilhada;

d) Estratégias de mitigação do aquecimento global cujo objetivo é a geração de inovações possibilitam melhor exploração das oportunidades geradas pela mudança climática;

e) A intensidade de contribuição da função produção para a mitigação da mudança climática está diretamente relacionada com o grau de inovação da estratégia escolhida pela empresa; e f) A contribuição da função produção para a estratégia de redução da mudança climática escolhida vincula-se diretamente à experiência da função produção em apoiar processos organizacionais complexos, tais como a implantação de sistemas de gestão da qualidade, gestão ambiental, planejamento e controle da produção, entre outros.

Assim, apesar da reflexão teórica, registram-se aqui importantes proposições para estudos práticos vindouros.

\title{
Straws in the wind of climate change: challenges, opportunities, and the role of production function in the context of global warming
}

\begin{abstract}
The aim of this paper is to enlighten the implications of climate change for organizations. To deal with this subject, the follow issues are analyzed: concept of environmental intelligence; opportunities which justify the adoption of these strategies, and the main role performed by the production function to implement such strategies. Finally, concepts of prior theoretical models are taken into account.
\end{abstract}

Keywords: Climate change. Production function. Environmental intelligence. Global warming.

\section{Referências bibliográficas}

ABOULNAGA, I. A. Integrating quality and environmental management as competitive business strategy for 21 st century. Environmental Management and Health, v. 9, n. 2, p. 65-71, 1998.

ANGELL, L. C.; KLASSEN, R. D. Integrating environmental issues into the mainstream: an agenda for research in operations management. Journal of Operations Management, v. 17, n. 5, p. 575-598, 1999.

BOIRAL, O. Global warming: should companies adopt a proactive strategy? Long Range Planning, v. 39, n. 3, p. 315-330, 2006.

BP. BP Sustainability Report. Disponível em: <www.bp.com>. 2006.

Acesso em: 15 mar. 2006

CD PROJECT. Carbon Disclosure Project. Disponível em: <www.cdproject.net>. 2007. Acesso em: 20 mar. 2007.

CORAZZA, R. I. Gestão ambiental e mudanças da estrutura organizacional. Revista de Administração de Empresas (RAE-eletrônica), v. 2, n. 2, p. 1-23, 2003.

DLUGOLECKI, A.; LAFELD, S. Climate change and the financial sector: an agenda for action. United Kingdom: Allianz Group and WWF, 2005.

DONAIRE, D. Gestão ambiental na empresa. São Paulo: Atlas, 1999.

EIATRACK. Eletronic Industries Alliance Regulatory Tracking Tool. Disponível em: <www.eiatrack.com>. 2007. Acesso em: 20 mar. 2007.

FLORIDA, R. Lean and green: the move to environmentally conscious manufacturing. California Management Review, v. 39, n. 1, p. 80-105, 1996.
GAUGHRAN, W. F.; BURKE, S.; PHELAN, P. Intelligent manufacturing and environmental sustainability. Robotics and Computer-Integrated Manufacturing, 2007. In press.

HOFFMAN, A. J. Climate change strategy: the business logic behind voluntary greenhouse gas reduction. California Management Review, v. 47, n. 3, p. 21-46, 2005.

JIMENEZ, J. B. L.; LORENTE, J. J. C. Environmental performance as an operations objective. International Journal of Operations \& Production Management, v. 21, n. 12, p. 1553-1572, 2001.

KOLK, A.; PINKSE, J. Business responses to climate change: identifying emergent strategies. California Management Review, v. 47, n. 3, p. 6-20, 2005.

KOLK, A.; PINKSE, J. Market strategies for climate change. European Management Journal, v. 22, n. 3, p. 304-314, 2004.

KUEHR, R. Environmental technologies: from a misleading interpretations to an operational categorization and definition. Journal of Cleaner Production, 2007. In press.

ROTHENBERG, S.; PIL, F. K.; MAXWELL, J. Lean, green, and the question for superior environmental performance. Production and Operations Management, v. 10, n. 3, p.228-243, 2001.

SARKIS, J.; RASHEED, A. Greening the manufacturing function. Business Horizons, September-October, 1995.

SCHULTZ, K.; WILLIAMSON, P. Gaining competitive advantage in a carbon-constrained world: strategies for European business. European Management Journal, v. 23, n. 4, p. 383-391, 2005. 
SMITH, M. T. Eco-innovation and market transformation. The Journal of Sustainable Product Design, v. 1, n. 1, p. 19-26, 2001.

TINGSTRÖM, J.; KARLSON, R. The relationship between environmental analyses and the dialogue process in product development. Journal of Cleaner Production, v. 14, n. 15-16, p. 1409-1419, 2006.
TONN, B. The Intergovernmental Panel on Climate Change: a global scale transformation initiative. Futures, v. 39, n. 5, p. 614-618, 2007.

WU, H. J.; DUNN, S. C. Environmental responsible logistics systems. International Journal of Physical Distribution \& Logistics Management, v. 25, n. 2, p. 20-38, 1995.

\section{Sobre os autores}

\section{Charbel José Chiappetta Jabbour}

Departamento de Administração - FEA-RP, Universidade de São Paulo - USP, Av. dos Bandeirantes, 3900, CEP 14049-000, Ribeirão Preto, SP, Brasil, e-mail: cjabbour@terra.com.br

\section{Fernando César Almada Santos}

Escola de Engenharia de São Carlos - EESC, Universidade de São Paulo - USP, Avenida Trabalhador Sancarlense, 400, CEP 13566-590, São Carlos, SP, Brasil, e-mail: almada@sc.usp.br

Agradecimento: À FAPESP, pelos recursos concedidos aos projetos em que este artigo se insere. 